\title{
REDUÇÃO DA DQO EM ESGOTO DOMÉSTICO UTILIZANDO SISTEMA BIOLÓGICO DE TRATAMENTO
}

\author{
REDUCTION OF COD IN HOUSEHOLD SEWAGE USING TREATMENT SYSTEM \\ BIOLOGICAL
}

P. M. P. BRANCO ${ }^{1 *}$, R. G. S. NOGUEIRA ${ }^{2}$, L. M. S. FERREIRA ${ }^{1}$, F. A. BORGES ${ }^{3}$, J. LUCAS JÚNIOR ${ }^{1}$

\section{RESUMO $^{1}$}

Tendo em vista as más condições sanitárias no país foi proposto a utilização da biodigestão anaeróbia como forma de tratamento de esgoto sanitário humano. Dessa forma, o objetivo foi avaliar a qualidade do efluente final, quanto ao parâmentro de DQO, para descarte adequado ou utilizar como adubo orgânico em pastagens para animais. $\mathrm{O}$ esgoto foi tratado por um biodigestor tubular associado a uma lagoa de estabilização. Foram colhidas 108 amostras (afluente e lagoa de estabilização). As análises foram realizadas no Laboratório de Biomassa I do Departamento de Engenharia Rural da FCAV/UNESP - Câmpus de Jaboticabal. As medidas de DQO foram realizadas em triplicata, segundo APHA (2005). Ao avaliar o sistema de tratamento pôde-se constatar que a média da DQO para o afluente foi de $320,68 \mathrm{mg} \mathrm{O}_{2} \mathrm{~L}^{-1}$ e na lagoa $150,61 \mathrm{mg} \mathrm{O}_{2} \mathrm{~L}^{-1}$, portanto obteve-se a eficiência de redução de, em média, de 50,20\%. Pode-se concluir esgoto doméstico que a eficiência de redução foi baixa, o que inviabiliza o descarte em corpos d'água e indica a necessidade de aliar um tratamento aeróbio ao anaeróbio.

PALAVRAS-CHAVE: Biodigrestão anaeróbia, biofertilizante, esgoto sanitário, saneamento básico

AGRADECIMENTOS: Cnpq e Copercana

ÁREA TEMÁTICA: Saúde Pública

\footnotetext{
${ }^{1}$ Faculdade de Ciências Agrárias e Veterinárias da Universidade Estadual Paulista (UNESP) - Câmpus de Jaboticabal * paulapilotto@hotmail.com

${ }^{2}$ Faculdade de Zootecnia e Engenharia de Alimentos da Universidade de São Paulo (USP) - Câmpus de Pirassununga ${ }^{3}$ Faculdade de Medicina Veterinária e Zootecnia da Universidade Federal do Mato Grosso do Sul (UFMS) - Câmpus de Campo Grande
} 